Sauntson, Helen ORCID:

https://orcid.org/0000-0002-0373-1242 (2021) 'Befriending' risks, vulnerabilities and challenges: Researching sexuality and language in educational sites. In: Cunningham, Clare ORCID:

https://orcid.org/0000-0003-3767-7624 and Hall, Christopher J ORCID: https://orcid.org/0000-0001-9038-1238, (eds.) Vulnerabilities, Challenges and Risks in Applied Linguistics. Bristol, Multilingual Matters

Downloaded from: http://ray.yorksj.ac.uk/id/eprint/5577/

The version presented here may differ from the published version or version of record. If you intend to cite from the work you are advised to consult the publisher's version: https://www.multilingual-matters.com/page/detail/Vulnerabilities-Challenges-and-Risks-inApplied-Linguistics/?k=9781788928236

Research at York St John (RaY) is an institutional repository. It supports the principles of open access by making the research outputs of the University available in digital form. Copyright of the items stored in RaY reside with the authors and/or other copyright owners. Users may access full text items free of charge, and may download a copy for private study or non-commercial research. For further reuse terms, see licence terms governing individual outputs. Institutional Repository Policy Statement

\title{
RaY
}

Research at the University of York St John

For more information please contact RaY at ray@yorks.ac.uk 


\section{'Befriending' risks, vulnerabilities and challenges: Researching sexuality and language in educational sites}

\section{Helen Sauntson York St John University, UK}

In recent years, there has been a steadily growing body of research on language and sexuality in educational settings. Research has developed in response to social, cultural and legal changes relating to sexual diversity in many places around the world. Sexuality is an important dimension of diversity and inclusion, yet in the broader field of applied linguistics, it often receives less attention that other dimensions of diversity, such as language background, nationality and ethnicity. For example, a simple search of Google Scholar for terms such as 'language', 'linguistics', 'applied linguistics' and 'diversity' in various configurations reveal a very limited focus on diversity in language(s) and in relation to race and ethnicity (and see Ahmed, 2007, for a useful discussion of the limited and constrained 'language of diversity').

Drawing on some of the most recent and ongoing research in the field, this chapter proposes that one reason for the relative marginalisation of language and sexuality within applied linguistics more broadly (and in the field of human sciences as a whole) is that it is seen as a particularly 'risky' and challenging area of research for many scholars. Much language and sexuality work tends to focus on language practices as they relate to sexual minority populations. Some work does, of course, explore heterosexual language practices. But the main dimension of heterosexuality explored in the field is the way that discourses of heteronormativity prevail in society and function to validate (certain forms of) heterosexuality as the perceived norm whilst marginalising other sexual identities. Indeed, this is a key remit of queer linguistics, an approach which has developed over the past two decades as a means of systematically exploring various aspects of the relationship between language and sexuality. The prevailing focus on sexual minorities presents numerous challenges which are explored throughout this chapter. Drawing on the concept of 'befriending' introduced by Pakula (2018), I propose some ways of dealing with the vulnerabilities, challenges and risks relating to this area of applied linguistics, rather than seeing them as a barrier to conducting and engaging with research. Pakula recognises the negative connotations associated with 'barriers' and 'risk' and subsequently reconceptualises them as 'befriending' in an effort to create a more positive discourse of engagement in sensitive or taboo areas of applied linguistic research and practice. Pakula's concept of befriending may ultimately be used as a way of addressing risks, vulnerabilities and challenges in other areas of applied linguistics and across the human sciences more broadly.

Researchers engaging in work exploring language and sexuality often report it as being risky and feeling vulnerable. These reports are often anecdotal, but there appear to be perhaps two key dimensions of perceived risk and vulnerability associated with conducting research in this area. The first dimension relates to riskiness in terms of engaging with a topic that is still seen as taboo in many contexts (despite the many positive social, cultural and legal changes taking place around the world). Researchers often report feeling that engaging in research on language and sexuality, as a taboo area, is potentially risky for their academic careers, particularly those who work in more conservative countries and contexts. This is particularly the case for those researchers in the field who, themselves, identify as LGBTQ+ which can already carry with it experiences of 'minority stress' (Balsam et al, 2013; Toomey, 2018). The second dimension of risk and vulnerability relates to the perceived and experienced 
vulnerability of research participants who identify as LGBTQ+. The vulnerability of LGBTQ+ populations in educational contexts is well-documented elsewhere (e.g. Birkett and Espelage, 2015; Bradlow et al, 2017; Bryan, 2012; DePalma and Francis, 2014; Gray, 2013; Kosciw et al, 2015; Meyer, 2010; Sauntson, 2013; 2018) but less attention has been paid to those researching these populations, including those researchers who may also identify themselves as LGBTQ+. Therefore, the rest of this chapter focuses on the vulnerabilities of researchers and the perceived and actual risks they take in conducting research in the field of language and sexuality.

In the following section, I firstly present some of my own personal reflections of conducting research in the field of language, sexuality and education (and within the broader academic context in the UK) over the past two decades. I then go on to consider some examples of current academic work in the field, which are particularly effective in terms of highlighting issues of risk and vulnerability as they relate to this area of applied linguistics research. Finally, I return to Pakula's notion of 'befriending' in order to consider how research in the area of language, sexuality and education may address some of the risks and vulnerabilities addressed in the current research.

\section{Personal reflections}

In language and sexuality work which focuses on educational contexts, much work points to the continuing ubiquity of discriminatory behaviours towards non-heteronormativity in educational settings. Yet applied linguistics research which investigates the linguistic forms of these discriminatory practices, and why they are so prevalent, is still in its relative infancy and conducted by relatively few scholars in a limited number of geographical contexts. A key reason for this, noted by Pakula (2018), is the risks associated with doing this research. We must acknowledge the important point that in certain geographies and temporalities educational settings constitute hazardous sites for exploring sexuality-related issues. Even in national contexts where same-sex relationships are legal (including the legalisation of samesex marriage and civil partnerships), negative social attitudes can still prevail. Such risks concern, amongst other things, putting the researcher's career in jeopardy and, thus, making ourselves professionally, as well as personally, 'vulnerable'.

This is relevant even in the UK context in which I have worked since 2000. There have been times when I have been explicitly advised not to research gender and sexuality, and times when I have been intimidated and even overtly bullied for being a gay woman and for pursuing social justice research. I have experienced environments characterised by hypercompetitiveness, aggression and fear. And, as Pakula stresses, both gender and sexuality are taboo concepts in the public discourse of some cultural contexts due to a politics of fear which, although subtle, is pervasive. This has manifested in a number of ways as I have been openly engaging in research projects which explore language and sexuality in educational settings, including schools.

For example, I have been advised on more than one occasion to not have language, gender and sexuality as my only or primary research area - as this is generally considered a 'risky' research area (in that it is potentially taboo) and is also not taken as seriously as other areas of applied linguistics. This of course is a result of classic feminist backlashes against any work which strives to expose inequality and injustice (Faludi, 1991; Silva and Mendes, 2015). Even though I still have much respect for the people who have advised me to maintain a more 'mainstream' research specialism alongside language and sexuality (e.g. language and education, or discourse analysis), I have, for the large part, continued to openly maintain 
language, sexuality and education as my research specialism. Interestingly, although this advice continued to be issued to be by different people throughout the early years of my career, they ended when I took up my position at my current institution. This suggests there is variability around different levels of acceptance of the field of language and sexuality across different institutions even within the same country. For myself, a way of addressing the risks that had been presented very explicitly to me by colleagues early in my career was to simply move to a more liberal and social justice-focused institution. However, it has to be acknowledged that this is not a viable option for many scholars for a variety of reasons.

Even within social justice-oriented institutions, challenges do remain. One of the biggest challenges I continue to experience is that audit is an inescapable feature of life as a university academic to the extent that many feel their primary purpose is to provide measures and validation of their work over and above the performance of the work itself. This happens even within the most liberal and progressive higher education contexts (for a discussion of the reasons for this, see, for example, Hall, 2018; Morrish and Sauntson, 2020). Within the overwhelmingly neoliberal context of British higher education, 'success' as an academic often becomes linked to these proxy measures. As Peseta et al (2017) argue:

The demand to count, measure, rank, quantify, evaluate and judge the work of universities (along with those who labour and study in them) haunts virtually all aspects of our work: from the quality of research, to targets for income generation, counts of patents, citations of articles and public testimonies of policy impact made visible and likeable online; from the quality of curriculum, to teaching with technology, responding to student feedback, watching the employment destinations and salaries of graduates as a comment on the value of their education; to whether a university is healthy, sustainable, sufficiently globalized or doing enough to position itself as the world leader in this or that discipline. (Peseta et al, 2017)

As individual scholars, we need to decide whether to go along with this, or try to navigate an alternative path to 'success' which is more collegiate, less individualised and more balanced with other aspects of life. These proxy measures of academic success can exacerbate the risks felt by researching particular topics in applied linguistics which are seen as marginal (and therefore less likely to be widely cited, achieve widespread and measurable 'impact' etc) and this is certainly something I have experienced as a challenge (and continue to experience) in my own professional life, particularly in relation to language and sexuality as a 'marginal' area within applied linguistics more broadly.

In some ways, this chapter is, in itself, risky. In addition to focusing on the taboo topic of sexuality (especially in educational settings), it may be read as critical of applied linguistics, and of higher education more broadly. And, in other national and geographical contexts, this chapter simply could not be written. For example, colleagues in areas of South America are currently experiencing unprecedented amounts of pressure and prejudice since the emergence of the political far right which has effectively 'closed down' social justice focused research, especially that which is seen to potentially destabilise ideas of normative gender and (hetero)sexuality. But progress in any human endeavour can only happen if brave people take risks and if they prioritise human advancement over their own personal safety and well-being. And this is precisely what has happened (and continues to happen) in the field of language and sexuality, especially in relation to education.

\section{Language, sexuality and education: Key issues in applied linguistics research}


It is not the intention to provide a comprehensive overview of work on language, sexuality and education here. Reviews of work in this area can be found in (Pakula, 2021; Sauntson, 2017; 2018). In this section, I simply highlight some issues in this area of research which have prompted the need for more attention to be paid to elements of risk and vulnerability and which, therefore, are more directly relevant to the concerns of the present chapter.

A key issue which has emerged in the field in recent years is that, despite some contextspecific claims that homophobia in schools is on the decline (e.g. McCormack, 2012), discriminatory behaviours, both verbal and non-verbal, in educational settings with reference to non-heteronormativity seem to continue to be ubiquitous (e.g. Bloomfield and Fisher, 2016; Connell, 2014; Meyer, 2010; Pascoe, 2011; Sauntson, 2018). This observation especially applies to secondary schools where maturing individuals enter the (hetero)sexual marketplace (Eckert 1996). Moreover, it is a finding which spans a range of international school contexts.

These findings have led to an examination of homophobic language and behaviour in schools from a range of disciplinary perspectives. Within applied linguistics, a valuable element of work in the field is that it does not exclusively focus on homophobic language and bullying (although this does, of course, continue to be an important element of research). There is acknowledgement that to focus exclusively on homophobic bullying and explicit homophobic language can only get us so far and often 'misses the point' about how and why heteronormative discourse prevail in educational contexts. The case studies of current research discussed in the following section shed light on why this may be the case, as well as revealing some of the risks associated with engaging with research that addresses these issues.

A shortcoming of existing work which focuses exclusively or overwhelmingly on homophobia language and homophobic bullying is that the field can become dominated by discourses about homophobia. Monk (2011) observes that homophobic bullying has become a legitimate object of social concern in recent years (to the point where it has become 'mainstreamed'), and this has become reflected in much sexualities and education research outside linguistics. Monk notes how, from the late 2000s in the UK, all three major political parties expressed concerns about homophobic bullying. A result of this mainstreaming is that homophobic bullying has been enabled to become a harm that can be spoken of with a concurrent breaking of taboos around sexual diversity which can mitigate the risk of researching it. However, Monk goes on to explain how homophobic bullying is a complex phenomenon and is actually a productive process contingent on various cultural and political factors. The dominant discourse of bullying in schools is one which is largely individualised - bullies are pathologised and victims are held responsible for the effects of bullying through having a displaying 'resilience'. Thus, homophobic bullying becomes situated within a broader 'law and order' discourse where there are clear 'perpetrators' and 'victims'. Monk argues that, within this discursive conceptualisation of bullying, structural forms of homophobia (and other forms of sexuality-based discrimination and harassment) get largely overlooked. Bullying at school (and in other contexts) is, in fact, the end point - it is what happens when sexuality and gender are not understood and when they are presented in constrained and highly limited ways. The examples of research discussed in the next section all explore this lack of understanding of how certain sexual identities become 'minoritised' from a linguistic perspective in different educational settings - in schools, children's picturebooks, language textbooks, and ESOL classrooms. These examples of current research all highlight different kinds of vulnerability and risk in their approach to researching 
language and sexuality in educational contexts. In drawing attention to these issues, I hope to emphasise the important contribution that applied linguistics can make to developing understanding of sexual diversity in educational settings and, ultimately, how to create more inclusive environments for both researchers and participants.

\section{'Taxonomies of risk' in researching language and sexuality}

Pakula (2018) importantly observes that, since language is conceived as a conduit of ideologies, which pertain to sexuality just as to other forms of social identity (see King, 2015), what is somewhat baffling to many is the fact that 'much current work on sexuality and education lacks [...] an explicit focus on the role that language plays in constructing discourses around sexuality in schools' (Sauntson, 2017: 147). Pakula offers several possible reasons for this. One reason is that the field is in its relatively early stages of development when compared with other areas of applied linguistics which have a much longer history. Related to this temporal issue, Pakula suggests that the role of language more broadly has been underestimated in certain contexts. In Poland, for example, language has frequently been perceived merely as a medium of instruction and not in terms of its constitutive functions i.e. as a conduit of constructing, deconstructing, normalizing and othering social relationships, identities and behaviours.

Another related reason, according to Pakula, is the risks associated with conducting research in this area. As I suggested earlier in my reflections of my own early career, such risks may concern putting the researcher's career in jeopardy. If this is the case even in the UK which is generally liberal in its attitudes towards sexual diversity, then in other geographies and temporalities, educational settings constitute extremely hazardous sites for exploring sexuality-related issues. Both gender and sexuality are taboo concepts in the public discourse of some cultural contexts (for example, Pakuła et al, 2015) due to a politics of fear (Wodak, 2015). Pakula posits that a further type of risk regards exploring innovative paradigms which may, or may not, enable the researcher to arrive at a fuller picture the language plays in shaping, constructing, and negotiating sexuality in and out of educational settings.

Pakula (2018) goes on to propose the idea of a 'taxonomy of risk' relating to the study of language and sexuality in educational settings. In doing so, he begins to theorise 'risk' from an applied linguistic perspective. Importantly, Pakula encourages researchers to be selfreflexive in asking whether the 'risk' is perceived or real, and in 'locating' the risk. He notes that language and sexuality is both overtly and covertly present in educational contexts and reviews work which has examined different linguistic manifestations of this and the ways that these manifestations may impact the researcher and their perceptions of 'risk' and 'feelings of 'vulnerability'. In incorporating these issues into a taxonomy of risk, Pakula draws on the work of Renn and Klinke (2005) who conceptualise risk and risk management from a scientific perspective. Pakula draws specific attention to the opening paragraph of Renn and Klinke's paper where they posit that 'risks must be considered as heterogeneous phenomena that preclude standardized evaluation and handling' (Renn and Klinke, 2005: S41). What this means in practice is that, although broad criteria for risk management can be drafted at a very general level, each research project should take on board not only theoretical perspectives of risk but also the project-specific practical applications of such theorisations. And an overriding principle is that applied linguists engaging in language, sexuality and education research (and other areas of research that entail risk and vulnerability) need to see themselves as risk managers. And an integral part of going about risks in any research project is firstly their identification, followed by analysis of them, and then coming up with ways of tackling them. Within this overarching framework, Pakula proposes two stages in applying a 
'taxonomy of risk' to a research project in language, sexuality and education. The first stage involves assessing whether the risk is perceived or real. For example, as researchers (especially those who identify as LGBTQ+), are we mapping our own fears onto the research process or is it a potential risk predicated on real-life social attitudes, political situations or the culture of the issue(s) under research? If the latter is the case, are we able to minimise the likelihood of such risks to enable the feasibility of the project?

The second stage in the taxonomy proposed by Pakula asks the question 'where is the locus of risk?'. Pakula proposes that there are three potential loci of risk in applied linguistics research on language, gender and sexuality: existential risk; linguistic and conceptual risk; and risk that involves experimenting with research paradigms. The first of these loci, existential risk, may be internal or external, according to Pakula. Internal existential risk involves engaging in research which has the potential to jeopardise the researcher's own career (see Weeks, 2006, for a discussion of how this is a particularly pertinent issue in sexuality-focused research). External risk refers to the research participants and their feelings of possibly feeling uncomfortable or endangered through their involvement in the research.

Linguistic and/or conceptual risks are the second locus of risk identified by Pakula. These risks relate to the use of particular words or concepts within a research project which may be perceived as taboo in the context under scrutiny. Pakula refers to his own work on analysing sexuality in English Language textbooks in Poland as an example of this locus of risk. Within this research project (Pakula et al, 2015), the researchers experienced resistance from participants in relation to the use of words which overtly describe non-heterosexual identity categories (e.g. gay, lesbian). This hostility can feel threatening for the researchers and may limit what they feel they are able to do or say in the research.

The third locus of risk in Pakula's approach focuses on experimenting with research paradigms. Language and sexuality has provided a platform for the development of new methodologies in applied linguistics research (e.g. queer linguistics and queer applied linguistics - see Leap, 2013; Motschenbacher, 2011; Motshenbacher and Stegu, 2013) as well as being known as a welcoming field for experimenting with innovative approaches and methods. In fact, a tenet of queer linguistics (and the queer theory that informs it) is that it resists methodological constraint, dominance or categorisation. It is, rather, characterised by what Leap (2020) terms a 'scavenger methodology' which allows for a great amount of variety in methodological approaches as well as encouraging experimentation with new approaches. But this can still feel risky to the researcher and leave them feeling vulnerable and open to criticism. And even if no criticism is forthcoming, Pakula argues researchers can still experience vulnerable feelings about whether their methods and approaches will 'catch on' with the wider scholarly community.

These issues can be further explored through references to examples of current work which examines different dimensions of language, sexuality and education but which have in common a shared focus on analysing manifestations of the overt and covert presence of heteronormativity in education. All of the projects go beyond a simple focus on language and bullying, and they also entail addressing various issues within Pakula's taxonomy of risk outlined above.

Firstly, work by McGlashan (2018) examines children's picturebooks featuring same-sex parents/caregivers and their use in UK schools. McGlashan notes that these books have become some of the most requested-to-be-banned books of modern times. This strongly 
suggests that, even in relatively liberal national contexts such as the UK, homosexuality and its representations in public life continues to be arguably the most controversial aspect of identity representation. Homosexuality is perceived as extremely threatening relative to other aspects of identity such as race and disability. This is probably due largely to problematic but pervasive discourses of sexuality as a 'choice'. McGlashan's research is innovative and risktaking not just in terms of the topic, but also in its ambitious but extremely valuable use of corpus-assisted multimodal critical discourse analysis.

McGlashan's findings suggest that the representations of same-sex parent families (SSPFs) in his picturebook corpus are underpinned by discourses of homonormativity and attempt to position families with same-sex parents as 'a different kind of family' rather than as something radically different from families with heterosexual parents. So SSPFs are still marked and therefore non-normative in the books comprising McGlashan's corpus. Normativity is premised upon things being unmarked in discourse. Despite this, McGlashan posits that provision of SSPF picturebooks in primary schools could provide educators with a vital resource for talking about familial and sexuality diversity.

Therefore, children's picturebooks containing SSPF representations may be one way of 'befriending the risks' associated with addressing sexual diversity through language practices in schools. The use of particular language teaching textbooks may be another way. In contrast to the huge number of analyses of gender representation in language textbooks, Sunderland (2018) observes that there have been very few on the representation of sexuality. Moreover, she notes that the lack of critical commentary on heteronormativity in language textbooks has been notable (some exceptions are: Thornbury, 1999; Gray, 2013; Pakula et al, 2015; Sunderland, 2015). Sunderland claims this is particularly surprising given Thornbury's accurate observation that ' $[\mathrm{g}]$ ]ayness is about as omitted [from foreign language textbooks] as anything can be' (Thornbury 1999: 15).

To partially address this, Sunderland's research considers and exemplifies the notion of 'degrees of heteronormativity'. She contends that language textbook heteronormativity is not a monolithic entity, but can be 'more' or 'less'. An example provided by Sunderland to illustrate this idea is as follows. A highly heteronormative text/image combination would be a two-parent nuclear family, mother and father who are sitting down to dinner with their teenage son and daughter, who are talking about the son's girlfriend and the daughter's boyfriend. Much less heteronormative would be a text/image concerning a group of female and male friends - no 'pairings' specified - enjoying a 'gender-neutral' activity such as hillwalking, which allows a range of readings in class about the different possible relationships between these people. Sunderland argues that textbook analysts can then consider a given textbook and look at the range and degrees of heteronormativities represented. Publishers themselves also have a degree of choice over what representations to include. Texts themselves may legitimately be considered as discriminatory under the 2010 Equality Act in that they can omit representation of particular identities and relationships, and/or misrepresent certain groups and identities, or present them in a negative way. Aldridge-Morris (2016: 80) highlights this issue and draws attention to the following specific paragraph in the Equality and Diversity UK Post-16 Education Toolkit document:

Equality and diversity have to be embedded into all aspects of the curriculum: [...] from inclusive resources and materials to teaching which explores the nature and impact of discrimination, harassment and victimisation because of disability, race, sex, sexual orientation, transgender, religion or belief, age and so on 
Given this legal context, Sunderland, perhaps optimistically, concludes that publishers can make a choice about what degrees of heteronormativity they want (or don't want) to represent. Like the picturebooks discussed by McGlashan, Sunderland importantly reminds us that language textbooks and children's picturebooks are, of course, guided by market forces and financial imperatives. It is arguably for this key reason that international textbooks are unlikely to feature non-heterosexual characters. Publishers will have to be willing to take (financial) risks if things really are to change in the future. But considering 'degrees of heteronormativity' may help publishers. Sunderland suggests one strategy they may implement is simply to move away from representations of extreme heteronormativity towards lower or lesser degrees of heteronormativity. Rather than directly including overt representations of same-sex romantic relationships, this may include, for example, more portrayals of single parents, same-sex friends and friendship groups (which allow a range of readings) and the inclusion of fewer explicitly heterosexual interest narratives.

This approach is potentially less risky to publishers in terms of the market forces they are driven by. The risks to researchers may also be reduced by this approach - analyzing degrees of heteronormativity may open up possibilities which are more liberating that setting out to analyse language textbooks in ways which focus only on the exclusion of non-heterosexual identities.

A final case study of current research on language, sexuality and education considered here is Baynham's ongoing work which explores LGBTQ+ inclusion issues in ESOL (English for Speakers of Other Languages) classrooms. Baynham argues, quite rightly, that this issue arises in the UK as a consequence of the 2010 Equality Act. This act consolidated nine previous pieces of legislation to create the UK's first unified equalities legislation. The Equality Act places a new duty on public services to: 'have due regard to the need to':

(a) eliminate discrimination, harassment and victimisation;

(b) advance equality of opportunity between persons who share a relevant protected characteristic and persons who do not share it;

(c) foster good relations between persons who share a relevant protected characteristic and persons who do not share it.'

(Equality Act, 2010: 96)

These legal edicts, Baynham argues, are relevant to the highly diverse ESOL student population in the UK. In considering ESOL classrooms as a specific educational setting within this legal framework, Baynham discusses three ways of understanding the positioning of LGBTQ+ teachers and students in a sexually normative world:

1. Invisibility/visibility: Within this dimension of the positioning of LGBTQ+ subjects, Baynham asks how visible LGBTQ lives are in the activities, practices and artefacts of the ESOL classroom.

2. Silencing and voice: This dimension of Baynham's work focuses on how audible LGBTQ+ voices (including both teachers, students and representations) are in ESOL classrooms and artefacts, or to what extent there is a culture of silence around manifestations of non-normative sexuality.

3. Space: In this third dimension, Baynham considers whether ESOL classrooms are safe, inclusive spaces for students and teachers whose sexuality is non-normative. 
Baynham considers the ESOL classroom as an element of the queer migration process, and students' narratives of migration and adaptation to life in the UK as part of a process of 'queering' the ESOL classroom. The ESOL classroom, of course, is an educational site in which LGBTQ+ asylum seekers have access to learning English. Given that asylum seekers may have escaped severely traumatic and potentially life-threatening situations when coming to the UK, it may well be quite alarming (and possibly trauma triggering) for these populations to then experience, at best, invisibility of LGBTQ+ identities and, at worse, explicit discrimination from others in the ESOL classroom. This may be confounded by parallel instances of implicit and overt racism and other forms of discrimination (see, for example, Motha, 2006; 2014).

Against this backdrop, Baynham considers a number of important questions pertaining to issues of vulnerability and risk in relation to sexuality issues in ESOL classrooms. He asks who should be responsible for addressing these issues and what ethical and political issues (which may themselves be considered 'risky') are involved. A further question centres around how to protect the privacy of LGBTQ+ teachers and students, including their right not to be out if they don't want to be. Baynham also draws explicit attention to research situations in which the classroom conversation may turn hostile, threatening and revealing of homophobic attitudes and behaviour.

More positively, and as a potential way of befriending these risks, Baynham makes reference to the creative arts and their place in ESOL and in applied linguistics more broadly. This particular befriending strategy resonates with some of my own research data from UK secondary schools, in which LGBTQ+-identified young people, who often report feeling ignored and invisible in school, also report making use of creative arts to increase their visibility and to authenticate themselves, especially through literature, music, drama and art. Other scholars, too, have identified the use of creative arts in schools as a means of befriending the risks associated with LGBTQ+ visibility and positive inclusion. Kjaran, Francis and Oddsson (2020), for example, explore the use of drama in schools in Iceland and South Africa to explore issues around sexual diversity. Calvelhe Panizo examines young gay men's aesthetic experiences of engaging with media texts in schools in Spain and finds that such an approach can be transformative (2020) and effective in terms of producing a 'queer counter-space' in schools.

\section{Ways forward? Strategies of 'befriending'}

The illustrative case studies on current and ongoing work in the field of language, sexuality and education discussed above reveal a number of possible 'befriending' strategies that could be explored and implemented as a means of addressing the frequent risks, vulnerabilities and challenges which pervade this area of applied linguistics research. These strategies could be of benefit to both researchers and participants (as well as to those participating in education beyond specific research projects). Within the educational contexts studied, the strategies identified include: the use of creative arts in classrooms (Baynham); the use of children's books containing representations of same-sex families (McGlashan); and greater exploitation of degrees of heteronormativity (and its concurrent alternatives) in language (and other kinds of) textbooks in schools. Beyond the educational research contexts themselves, I would suggest a number of wider befriending strategies, all of which require varying acts of bravery not just from researchers themselves, but from allies and colleagues working in other areas of applied linguistics. 
Firstly, as argued by Sunderland, publishers must be willing to take more risks in terms of including positive representations of diverse gender and sexual identities in their materials, including books for both children and adults (e.g. adult learners of English). Whilst publishers are generally supportive of publishing research work in the field of language, sexuality and education, this has yet to translate into publishers' pedagogic material for use in schools and other kinds of educational settings.

My own personal reflections also reveal a need for institutional support for those conducting research in the field of language, sexuality and education (and, arguably, language and sexuality more broadly). The institutions in which researchers are employed must be willing to befriend the inevitable risks associated with the research field, in ways that ensure their employees and students are fully supported. This may entail a straightforward checking in with practices that already take place, such as ensuring colleagues engaged in sexuality-based research are being supported through conference funding, the fair allocation of research leave and so on. But beyond this, institutions could also consider ways of providing spaces and systems of support whereby researchers can 'offload' after and during engagement with risky research. This is already established practice in some professional areas such as psychology and counselling. Extending this to researchers in linguistics, and in any other discipline, who may be engaged in research that exposes risks and vulnerabilities could help to create a context which is less isolating for those researchers. There may be a case to be made for additional support to be made available to LGBTQ+ researchers which take into account experiences frequently associated with 'minority stress' as well as the vulnerabilities which may be exposed through the research being conducted. Another suggestion for institutions may be for issues around researcher risk and vulnerability to be explicitly addressed through ethics processes and practices, if this is not currently the case.

As well as individual institutional support, researchers in this area would benefit from organisational support from professional organisations such as BAAL (and parallel organisations in other countries) and AILA. Professional organisations may therefore be asked to befriend the risks and vulnerabilities associated with their members conducting research in the area of language, sexuality and education. Practical suggestions for achieving this may include organisations including sections on 'vulnerable populations' in their ethics guidelines. Organisations could operate peer support networks for researchers engaging in risky research, along similar lines to the way that some professional organisations already operate mentoring schemes for researchers. It may even be possible for organisations to hold specific events (e.g. workshops, conferences) dedicated to exploring these kinds of issues.

Beyond institutional and professional organisational befriending practices, we should also consider the wider higher education context. As briefly discussed earlier, we know that in a neoliberal era, academic freedom, ethics, social justice, democracy and humanitarian practices are all increasingly under threat. But within the neoliberal system, there are, arguably, small pockets of resistance that can be found in places such as co-operative universities, liberal arts colleges, small specialist universities and some Cathedrals group universities (which have an avowed commitment to faith and social justice values as part of their mission). Can these kinds of educational contexts provide safer platforms from which research on language, sexuality and education can truly develop, flourish and make a real difference? This final question perhaps embodies an appeal to vice-chancellors to be brave and to befriend the risks involved in applied linguistics (and other) research driven primarily by an emancipatory and social justice agenda. 


\section{References:}

Ahmed, S. 2007. The language of diversity. Ethnic and Racial Studies 30 (2): 235-256. Aldridge-Morris, K. 2016. How to Write ESOL Materials. Oxford: ELT Teacher 2 Writer. Balsam, K., Beadnell, B. and Molina, Y. 2013. The daily heterosexist experiences questionnaire: Measuring minority stress among lesbian, gay, bisexual, and transgender adults. Measurement and Evaluation in Counseling and Development 46 (1): 3-25. Baynham, M. 2018. Queer voices in the ESOL classroom. Paper presented at the British Association of Applied Linguistics Annual Meeting, York St John University, UK, 6-8 September 2018.

Birkett, M. and Espelage, D. 2015. Homophobic name-calling, peer-groups, and masculinity: The socialization of homophobic behaviour in adolescents. Social Development 24 (1): 184205.

Bloomfield, V. and Fisher, M. 2016. LGBTQ Voices in Education: Changing the Culture of Schooling. London: Routledge.

Bradlow, J., Bartram, F., Guasp, A. and Jadva, V. 2017. School Report: The Experiences of Lesbian, Gay, Bi and Trans Young People in Britain's Schools in 2017. London: Stonewall. Bryan, J. 2012. From the Dress-up Corner to the Senior Prom. Plymouth: Rowman and Littlefield.

Calvelhe Panizo, L. 2020. Gay teenage boys' experiences and usages of the media in Spain: Educational implications. In J.I. Kjaran and H. Sauntson (eds) Schools as Queer Transformative Spaces: Global Narratives on Sexualities and Genders. London: Routledge. 178-188.

Connell, C. 2014. School's Out: Gay and Lesbian Teachers in the Classroom. Berkeley, CA: University of California Press.

DePalma, R. and Francis, D. 2014. The gendered nature of South African teachers' discourse on sex education. Health Education Research 29(4): 624-32.

Eckert, P. 1996. Vowels and nail polish: The emergence of linguistic style in the preadolescent heterosexual marketplace. In N. Warner et al (eds) Gender and Belief Systems. Berkley: Berkley Women and Language Group, 183-190.

Equality Act (UK) 2010. http://www.legislation.gov.uk/ukpga/2010/15/contents

Faludi, S. 1991. Backlash: The Undeclared War Against Women. London: Vintage.

Gray, J. (ed) 2013. Critical Perspectives on Language Learning Materials. Basingstoke: Palgrave.

Hall, R. 2018. The Alienated Academic: The Struggle for Autonomy Inside the University. Basingstoke: Palgrave.

King, B. 2015. Language and sexuality in education. In P. Whelehan and A. Bolin (eds) The International Encyclopedia of Human Sexuality. New York: Wiley-Blackwell. 649-719. Kjaran, J.I., Francis, D. and Oddsson, A.H. 2020. Creating a queer counter-space in high schools in Iceland and South Africa: A drama-inspired pedagogical approach. In J.I. Kjaran and H. Sauntson (eds) Schools as Queer Transformative Spaces: Global Narratives on Sexualities and Genders. London: Routledge. 17-34.

Kosciw, J., Greytak, E., Giga, N., Villenas, C. and Danischewski, D. 2015. The 2015 National School Climate Survey: The Experiences of Lesbian, Gay, Bisexual, Transgender, and Queer Youth in Our Nation's Schools. New York: GLSEN.

Leap, W. 2013. Commentary II: Queering language and normativity. Discourse and Society 24 (5): 643-648.

Leap, W. 2020. Language Before Stonewall: Language, Sexuality, History. Basingstoke: Palgrave.

McCormack, M. 2012. The Declining Significance of Homophobia. How Teenage Boys are 
Redefining Masculinity and Heterosexuality. Oxford: Oxford University Press.

McGlashan, M. 2018. Same-sex parents in children's picturebooks: Examining representations and their place in the curriculum. Paper presented at the British Association of Applied Linguistics Annual Meeting, York St John University, UK, 6-8 September 2018.

Meyer, E. 2010. Gender and Sexual Diversity in Schools: An Introduction. London: Springer. Monk, D. 2011. Challenging homophobic bullying in schools: The politics of progress. International Journal of Law in Context 7 (2): 181-207.

Morrish, L. and Sauntson, H. 2020. Academic Irregularities: Language and Neoliberalism in Higher Education. London: Routledge.

Motha, S. 2006. Racializing ESOL teacher identities in US K-12 public schools. TESOL Quarterly 40 (3): 495-518.

Motha, S. 2014. Race, Empire, and English Language Teaching: Creating Responsible and Ethical Anti-Racist Practice. New York: Teachers College Press.

Motschenbacher, H. 2011. Taking queer linguistics further: Sociolinguistics and critical heteronormativity research. International Journal of the Sociology of Language 212: 149179.

Motschenbacher, H. and Stegu, M. 2013. Queer linguistic approaches to discourse: Introduction. Discourse and Society 24 (5): 519-535.

Pakula, L. 2018. Befriending the risk(s): Exploring sexuality and language in educational sites. Paper presented at the British Association of Applied Linguistics Annual Meeting, York St John University, UK, 6-8 September 2018.

Pakula, L. (ed) 2021. Linguistic Perspectives on Sexuality in Education: Representations, Constructions, and Negotiations. Basingstoke: Palgrave.

Pakuła, Ł., Pawelczyk, J. and Sunderland, J. 2015. Gender and Sexuality in English Language Education: Focus on Poland. London: British Council.

Pascoe, C. J. 2011. Dude, You're a Fag: Masculinity and Sexuality in High School. Berkeley, CA: University of California Press.

Peseta, T., Barrie, S. and McLean, J. 2017. Academic life in the measured university:

Pleasures, paradoxes and politics. Higher Education Research and Development 36 (3): 453 457.

Renn, O. and Klinke, A. 2004. Systemic risks: A new challenge for risk management. EMBO Reports 5 (Supplement 1): S41-S46.

Sauntson, H. 2013. Sexual diversity and illocutionary silencing in the English National Curriculum. Sex Education: Sexuality, Society and Learning 13(4): 395-408.

Sauntson, H. 2017. Language, sexuality and education. In S. Wortham et al (eds)

Encyclopedia of Language and Education: Discourse and Education. New York: Springer. 147-159.

Sauntson, H. 2018. Language, Sexuality and Education. Cambridge: Cambridge University Press.

Silva, K. and Mendes, K. (eds) 2015. Feminist Erasures: Challenging Backlash Culture. Basingstoke: Palgrave.

Sunderland, J. 2015. Gender (representation) in foreign language textbooks: Avoiding pitfalls and moving on. In S. Mustapha and S. Mills (eds) Gender Representations in Learning Materials: International Perspectives. London: Routledge. 19-34.

Sunderland, J. 2018. Exploring the representation of sexuality in foreign language textbooks. Paper presented at the British Association of Applied Linguistics Annual Meeting, York St John University, UK, 6-8 September 2018.

Thornbury, S. 1999. Window-dressing vs. cross-dressing in the EFL sub-culture. Folio 5 (2): $15-17$.

Toomey, R. 2018. Coping with sexual orientation-related minority stress. Journal of 
Homosexuality 65 (4): 484-500.

Weeks, J. 2006. The social construction of sexuality. In S. Seidman, N. Fischer and C. Meeks (eds) The Handbook of the New Sexuality Studies. London: Routledge. 14-20.

Wodak, R. 2015. The Politics of Fear: What Right-Wing Populist Discourses Mean. London: Sage. 